\title{
Relacionamento Mãe-Primogênito durante a Gestação do Segundo Filho ${ }^{1}$
}

\author{
Caroline Rubin Rossato Pereira ${ }^{2}$ \\ Cesar Augusto Piccinini \\ Universidade Federal do Rio Grande do Sul
}

\begin{abstract}
RESUMO - O presente estudo investigou as impressões de oito mães, que responderam a uma entrevista sobre seu relacionamento com o primogênito durante a gestação do segundo filho. A partir de uma análise de conteúdo, os resultados revelaram que a nova gestação trouxe-lhes a necessidade de uma redefinição em sua identidade materna e em sua relação com o primogênito. Além de voltar-se emocionalmente para o bebê, as restrições físicas da gestação trouxeram limitações à interação mãe-primogênito, tanto em brincadeiras como nos cuidados diários. Destaca-se ainda o aumento no apoio fornecido pelo casal parental ao primogênito. Os resultados sugerem a importância da rede de apoio e de programas de intervenção para famílias envolvidas na transição para o nascimento do segundo filho.
\end{abstract}

Palavras-chave: relação mãe-primogênito; gestação; segundo filho.

\section{Relationship between Mother and First-Born Child during her Second Pregnancy}

\begin{abstract}
The present study investigated impressions and feelings of eight mothers who were interviewed concerning the relationship with their firstborn child during the pregnancy of their second child. Based on content analysis, the results indicated that the new pregnancy required a redefinition of mother's relationship with her firstborn child and of her maternal identity. Because mother was emotionally involved with the baby, as well as physical restrictions of the pregnancy, limitations of the interaction between the mother and her firstborn child during play and in daily care were reported. The results suggest the importance of the family's social network and, eventually, the necessity of intervention programs for families involved in the transition process of having a second child.
\end{abstract}

Keywords: mother-firstborn relationship; pregnancy; second child.

O nascimento de uma criança modifica de uma só vez a organização familiar (organização material, distribuição do espaço e do tempo) e as relações entre os membros da família (Kreppner, Paulsen \& Schuetze, 1982). Contudo, este não seria um processo abrupto, finito ou necessariamente concomitante ao evento em si. No caso específico do nascimento do segundo filho, a sua integração poderia ser pensada como uma longa cadeia de interações familiares ao longo das quais ocorreriam mudanças e trocas entre todos os membros da família (Kreppner e cols., 1982). Deste modo, a família responderia a este evento mesmo antes que ocorresse de fato. Neste sentido, Bourguignon e cols. (1980) defendem que o período da gestação se constituiria em um momento importante de adaptação, permitindo a modificação da percepção da família por seus membros e o início da redefinição de seu funcionamento.

Contudo, grande parte dos estudos examinados destaca o impacto do nascimento do segundo filho sobre a relação mãe-primogênito com enfoque especial para o período pós-parto. A este respeito, as evidências apontam para uma diminuição na freqüência e na qualidade afetiva das interações mãe-primogênito (Dunn \& Kendrick, 1980, 1986; Field \&

1 Este artigo é baseado em parte da dissertação de mestrado de Caroline Rubin Rossato Pereira, apresentada no Curso de Pós-Graduação em Psicologia da Universidade Federal do Rio Grande do Sul sob a orientação do Prof. Dr. Cesar Augusto Piccinini.

2 Endereço para correspondência: Pe. Gabriel Bolzan, 1777, no. 82. Santa Maria, RS. CEP 97095-500. Fone: (55)9641-1033 ou (55)3027-2636.

E-mail: carolinerrp@gmail.com
Reite, 1984; Stewart, Mobley, Van-Tuyl \& Salvador, 1987), assim como aumento na provisão de atividades de aprendizagem ao primogênito após o nascimento do segundo filho (Kowaleski-Jones \& Dunifon, 2004).

Dimensões importantes da relação do primogênito com seus genitores podem mudar de forma intensa com o nascimento do irmão (Baydar, Greek \& Brooks-Gunn, 1997). Estas mudanças ocorreriam tanto a um nível comportamental quanto a um nível mais abstrato, incluindo as percepções e emoções dos envolvidos. A freqüência e a qualidade afetiva das interações e o estilo disciplinar dos pais seriam alguns aspectos afetados nesta transição, os quais poderiam estar mediando a reação do primogênito ao nascimento do irmão. A este respeito, Stewart, Mobley, Van-Tuyl e Salvador (1987) afirmaram que as mudanças no comportamento do primogênito seriam estratégias para reaver as interações e a atenção desfrutada até o momento com os progenitores. $\mathrm{Na}$ perspectiva da Teoria do Apego (Bowlby, 1984), o grande impacto vivido pela criança com o nascimento de um irmão está associado ao risco que este impõe ao acesso da criança à sua fonte primária de apego, a mãe.

Há indicações, de que a relação mãe-primogênito altere-se ainda na gestação do novo irmão, e que estas difiram daquelas que deverão ocorrer após o nascimento do segundo filho (Kowaleski-Jones \& Dunifon, 2004). Os estudos referentes ao período gestacional do segundo filho, tendem a tomar como foco as preocupações e angústias vividas pela mãe (Bourguignon \& cols., 1980; Jenkins, 1976; Richardson, 1983; Walz \& Rich, 1983). Segundo estes estudos, as 
principais preocupações maternas no período da gestação do segundo filho, incluiriam a perda da relação especial mãe-primogênito, a promoção da aceitação do novo irmão por parte do primogênito (Richardson, 1983; Walz \& Rich, 1983) e, com relação a seu papel de mãe, preocupações quanto a suas capacidades físicas e afetivas de satisfazer as necessidades das duas crianças e amá-las igualmente (Jenkins, 1976; Murphy, 1993).

Endossando estas idéias, o estudo de Richardson (1981), realizado por meio de entrevistas com 14 gestantes norte-americanas (cinco esperavam o primeiro filho, cinco o segundo e quatro delas o terceiro ou quarto filho), revelou que a gestação era percebida como um período de grandes mudanças sociais, independente de quantos filhos as mulheres já possuíssem. Na redefinição de suas relações, a reorganização das atividades interpessoais e das responsabilidades entre os indivíduos apareceu como uma tarefa crítica. Neste sentido, as mães que já possuíam ao menos um filho, descreveram os relacionamentos estabelecidos com o marido e com os filhos como os mais problemáticos ao longo da gestação. Aproximadamente um terço das relações com o marido e metade das relações com os filhos foram apontadas como insatisfatórias, de modo que, na maioria das vezes, a mãe investia muito de sua energia nestas relações, encorajando mudanças na direção de suas expectativas.

Segundo Richardson (1983) o sentimento de distância emocional constituiu-se em um dos principais temas abordados pelas mães ao retratar sua relação com o primogênito durante a gestação. Conforme o autor, as mães relataram não compreender a criança, de modo que não podiam prever sua reação e seus comportamentos neste período. Somado a isso, a necessidade crescente de contar com outras pessoas para o cuidado do primogênito e o seu envolvimento com outros cuidadores era vivido com tristeza pela mãe, que sentia como se estivesse perdendo seu lugar especial dentre as relações do filho. Richardson destacou também que, no final da gestação, as mães estariam sobrecarregadas e menos aptas a lidar com o primogênito, o qual se tornava crescentemente exigente e mal-comportado. Neste período, a relação com o primogênito foi percebida pelas mães como predominantemente insatisfatória. Na verdade, já ao longo da gestação era evidente para as mães que as crianças percebiam desde cedo que sua posição na família estava em risco, sendo que todas elas relataram algum grau de resistência do primogênito ao nascimento do irmão.

A aceitação do novo irmão pelo primogênito e a reformulação do relacionamento mãe-primogênito foram também destacadas pelas participantes do estudo de Walz e Rich (1983). Segundo os autores, nos três dias de internação hospitalar subseqüentes ao nascimento do segundo filho, a relação mãe-primogênito tornara-se fonte de grandes preocupações para as mães. Com o nascimento do bebê, elas previam um rompimento na relação diádica íntima e exclusiva com o primogênito, o que era vivenciado com sofrimento. Em acréscimo, o primogênito lhes parecia vulnerável e necessitando de cuidados especiais para adaptar-se a este período. Os autores apontaram que as mães despendiam considerável tempo e energia buscando a aceitação do segundo filho por parte do primogênito, seja através da preparação da criança para o nascimento do irmão, seja através da inclusão do primogênito nos eventos referentes à chegada do irmão. Assim, a aceitação do irmão, também destacada por Richardson (1983), foi a tarefa chave apontada pelas mães para a realização do seu ideal de maternidade, dependendo disso para uma incorporação bem sucedida do novo membro à vida da família e para a reformulação dos papéis e das relações familiares.

Em contraste com o panorama apresentado anteriormente, Kowaleski-Jones e Dunifon (2004) salientaram que o período gestacional seria caracterizado por uma melhora no bem-estar sócio-emocional do primogênito, com aumento na atenção dispensada pelos progenitores à criança enquanto buscam prepará-lo para a chegada do irmão. A importância de tal evidência encontra-se no fato de que, conforme Gottlieb e Mendelson (1990), o apoio materno durante a gestação, somado ao nível de aflição do primogênito neste período e ao apoio paterno no período pós-parto, esteve diretamente relacionado à aflição sentida pelo primogênito após o nascimento do bebê. Os autores definiram apoio parental como expressão de afeto positivo, endossamento dos comportamentos, percepções ou opiniões da criança e provisão de ajuda material ou simbólica à criança.

Dunn e Kendrick (1986) e Teti, Sakin, Kucera, Corns e Eiden (1996) endossaram esta idéia ao afirmarem que o apoio parental e o envolvimento afetivo da mãe com o primogênito, ainda na gestação, beneficiariam o ajustamento da criança que, como conseqüência, apresentaria menores níveis de estresse no período pós-parto. Em contrapartida, algumas evidências sugerem que primogênitos que experienciaram mais confrontação com a mãe (i.e. proibições e limitações freqüentes) no período pré-natal, tenderam a reagir mais negativamente ao nascimento do bebê (Dunn \& Kendrick, 1986). Isto indica que as experiências e sentimentos do primogênito no período da gestação podem ser importantes indicadores quanto à sua reação ao nascimento do irmão.

Conforme a revisão apresentada percebe-se a falta de consenso na literatura acerca da qualidade da relação mãe-primogênito durante a gestação do segundo filho. Enquanto vários estudos indicam a gestação como um período de maior confrontação, irritabilidade e dificuldades na relação mãe-primogênito, outros revelaram melhorias nos relacionamentos e no bem-estar do primogênito. Além disso, destaca-se a carência de estudos atuais que investiguem esta temática no período gestacional, sendo que grande parte desta literatura é das décadas de 1980 e 1990, particularmente norte-americana ou européia . Tal escassez contribui para a persistência da idéia de que as mudanças na vida familiar e na relação mãe-primogênito só seriam perceptíveis após o nascimento do irmão, quando o primogênito e os progenitores poderiam concretizar a alteração da configuração familiar.

Assim, o objetivo do presente estudo foi investigar as impressões e sentimentos maternos sobre o relacionamento mãe-primogênito durante a gestação do segundo filho. Esperava-se que com a gravidez seriam relatadas mudanças na relação mãe-primogênito, com destaque para dificuldades da mãe para lidar com o primogênito, além da necessidade de redefinir sua relação com este. 


\section{Método}

\section{Participantes}

Participaram do estudo oito mães que se encontravam no último trimestre de gestação do segundo filho e possuíam um único filho em idade pré-escolar (entre três anos e quatro meses e cinco anos e dez meses). Todas as mães residiam na região metropolitana de Porto Alegre (RS), eram casadas e o marido era o pai de seus dois filhos. Elas tinham idades entre 31 e 43 anos e possuíam nível socioeconômico entre médio e alto. Quanto à escolaridade, elas tinham entre ensino médio incompleto e pós-graduação, sendo que a maioria possuía, no mínimo, o ensino superior completo. Todas as mães trabalhavam no momento da realização do estudo. A Tabela 1 apresenta os dados sociodemográficos das participantes.

Todas as participantes do presente estudo faziam parte de um projeto longitudinal maior intitulado Estudo longitudinal sobre o impacto do nascimento do segundo filho na dinâmica familiar e no desenvolvimento emocional do primogênito - ELSEFI (Piccinini, Lopes, Rossato \& Oliveira, 2005), realizado pelo Núcleo de Infância e Família (NUDIF) do Instituto de Psicologia da Universidade Federal do Rio Grande do Sul. Este projeto, iniciado em 2005 objetivou investigar os aspectos subjetivos e comportamentais da relação pai-mãe-primogênito, bem como o impacto do nascimento do segundo filho no relacionamento familiar e no desenvolvimento emocional do primogênito. Para tanto, o estudo iniciou acompanhando 48 famílias que possuíam um primogênito em idade pré-escolar (três a seis anos). Destas, em 27 famílias a mãe estava grávida do segundo filho no momento do contato inicial, e as demais 21 famílias, possuíam um único filho e a mãe não estava grávida. Todas as mães e pais do ELSEFI moravam juntos com os filhos e o pai também foi convidado a participar do estudo. Os participantes do estudo longitudinal foram contatados através de diversas instituições de saúde (hospitais e unidades sanitárias) e de ensino (creches, escolas de educação infantil, escolas de ensino fundamental) da cidade de Porto Alegre, bem como por meio de indicações.

Dentre as participantes do presente estudo, quatro foram contatadas através de escolas de educação infantil e quatro através de indicação. Na seleção dos casos se buscou abranger as quatro possíveis combinações de sexo dos filhos (primogênito masculino/segundo filho masculino; primogênito masculino/segundo filho feminino; primogênito feminino/ segundo filho feminino; primogênito feminino/segundo filho masculino), de modo que foram selecionadas duas famílias de cada uma destas combinações. O presente estudo foi avaliado e considerado ética e metodologicamente adequado pelo Comitê de Ética e Pesquisa da Universidade Federal do Rio Grande do Sul.

\section{Delineamento, procedimentos e instrumentos}

O delineamento de estudo de casos coletivos (Stake, 1994) foi utilizado para investigar as impressões e sentimentos maternos sobre o relacionamento mãe-primogênito durante a gestação do segundo filho. Com este delineamento, objetivou-se examinar tanto as semelhanças quanto as particularidades entre os casos, visando uma compreensão aprofundada do fenômeno estudado.

A apresentação do estudo às mães e o convite para participarem da pesquisa foram realizados através das instituições de contato mencionadas acima, ou via ligação telefônica no caso de indicações individuais. Após o consentimento da instituição de contato, as mães que se dispuseram a participar da pesquisa preencheram uma Ficha de Contato Inicial (NUDIF, 2005a) e foi agendado um encontro para a realização das entrevistas, o qual poderia ocorrer na residência, na instituição de contato, no local de trabalho, ou numa sala da universidade. Neste encontro subseqüente, as mães foram solicitadas a assinar o Termo de Consentimento Livre e Esclarecido e preencher a Entrevista de Dados Demográficos do Casal (NUDIF, 2005b). Além disso, foram realizadas a Entrevista sobre a Gestação e as Expectativas da Gestante (NUDIF,

Tabela 1. Dados Sociodemográficos das Participantes

\begin{tabular}{|c|c|c|c|c|c|c|c|}
\hline Mãe & $\begin{array}{l}\text { Idade } \\
\text { Mãe }\end{array}$ & $\begin{array}{c}\text { Escolaridade } \\
\text { Mãe }\end{array}$ & $\begin{array}{l}\text { Ocupação } \\
\text { Mãe }\end{array}$ & $\begin{array}{c}\text { Idade } \\
\text { Primogênito }\end{array}$ & $\begin{array}{c}\text { Sexo } \\
\text { Primogênito }\end{array}$ & $\begin{array}{c}\text { Sexo } \\
2^{\circ} \text {. filho }\end{array}$ & $\begin{array}{c}\text { NSE* }^{*} \\
\text { da família }\end{array}$ \\
\hline M1 & 32 & Sup. Comp. & Psicóloga & 4a $5 \mathrm{~m}$ & Fem. & Fem. & 5 \\
\hline M2 & 31 & Médio comp. & Secretária & $5 \mathrm{a}$ & Masc. & Masc. & 3 \\
\hline M3 & 34 & Sup. Incomp. & Vendedora & $4 \mathrm{a} 3 \mathrm{~m}$ & Masc. & Fem. & 4 \\
\hline M4 & 38 & Sup. Comp. & Psicóloga & $5 \mathrm{a} 10 \mathrm{~m}$ & Fem. & Masc. & 5 \\
\hline M5 & 33 & Sup. Comp. & Nutricionista & $4 \mathrm{a} 8 \mathrm{~m}$ & Fem. & Fem. & 5 \\
\hline M6 & 39 & Pós-grad. & Agrônoma & $4 a$ & Masc. & Masc. & 5 \\
\hline M7 & 34 & Pós-grad. & Professora & $4 \mathrm{a} 11 \mathrm{~m}$ & Fem. & Masc. & 5 \\
\hline M8 & 43 & Médio incomp. & Téc. Enferm. & $3 \mathrm{a} 4 \mathrm{~m}$ & Masc. & Fem. & 3 \\
\hline
\end{tabular}

* Nível socioeconômico com base em Hollingshead (1975; adaptado por Tudge \& Frizzo, 2002): 1(baixo); 2 (médio-baixo); 3 (médio); 4 (médio-alto) e 5 (alto). 
2005c), na qual examinaram-se as impressões e sentimentos das mães sobre a gestação do seu segundo filho e expectativas quanto ao seu nascimento (ex. história da gestação, principais preocupações, mudanças corporais; reações do marido, familiares e amigos perante a notícia da gestação; apoio recebido de amigos, parentes ou profissionais; expectativas quanto às características do bebê, relacionamento mãe-bebê e relacionamento pai-bebê; relacionamento conjugal e apoio de familiares, amigos e profissionais); e a Entrevista com a Mãe sobre o Impacto da Gestação do Segundo Filho na Dinâmica Familiar (NUDIF, 2005d), em que buscou-se examinar o impacto da gestação do segundo filho sobre diversos aspectos da dinâmica familiar (ex. reações e sentimentos do primogênito em relação à notícia da gravidez; curiosidades, preocupações e interesses quanto à gravidez e aos bebês; interação com o bebê na barriga; relacionamentos com os pais, familiares, amigos e outras crianças; preparação do primogênito para a hospitalização da mãe e a chegada do irmão; rotina familiar e o relacionamento conjugal).

Em um segundo encontro, foi realizada a Entrevista sobre a Experiência da Maternidade (NUDIF, 2005e), que investigou aspectos da experiência da maternidade em relação ao primogênito no contexto da gestação do segundo filho (ex. sentimentos e dificuldades experienciados pela mãe; autopercepção como mãe; atividades e tarefas assumidas com o primogênito; situações estressantes vivenciadas; percepção da mãe quanto ao seu marido como pai; relação da mãe com outras pessoas que auxiliem no cuidado do primogênito).

\section{Resultados}

A análise de conteúdo qualitativa (Bardin, 1977; Laville \& Dionne, 1999) foi utilizada para se examinar os relatos das mães sobre suas impressões e sentimentos acerca do relacionamento mãe-primogênito durante a gestação do segundo filho. A este respeito, buscou-se examinar a qualidade da relação conforme avaliada pelas mães e, fundamentalmente, as mudanças percebidas pelas mães em seu relacionamento com o primogênito durante sua gravidez.

Para fins de análise, as respostas das mães às entrevistas foram agrupadas conforme estivessem relacionados prioritariamente à mãe ou ao primogênito, tomando por base duas categorias de análise derivadas das próprias entrevistas: Mudanças centradas na mãe; Mudanças centradas no primogênito. Obviamente, trata-se de uma divisão para fins de análise, já que há uma interdependência e influência mútua dos comportamentos da mãe e do primogênito na qualidade de seu relacionamento. Dois codificadores, a primeira autora deste artigo e uma bolsista de Iniciação Científica, classificaram todos os relatos das participantes e eventuais discordâncias foram eliminadas através de discussão até que se chegasse a um consenso. A seguir, caracterizam-se cada uma das categorias, ilustrando-as com relatos das próprias mães

\section{Mudanças centradas na mãe}

Nesta categoria foram investigadas as mudanças relatadas pelas mães em seu modo de relacionar-se com o primogênito durante a gestação. Tomou-se como foco as mudanças centradas na própria mãe. Em particular, as mães destacaram três aspectos: limitação física decorrentes da gravidez ou associadas à gravidez, mudanças na atenção dispensada ao primogênito e mudança na tolerância/irritação com o primogênito.

No que se refere ao primeiro aspecto, todas as mães relataram alguma mudança na sua relação com o primogênito em conseqüência das limitações físicas associadas à gestação ${ }^{3}$. Com o crescimento da barriga e as restrições características do último trimestre gestacional as mães destacaram as seguintes alterações: impossibilidade de pegar o primogênito no colo, limitações nas brincadeiras e redução do envolvimento da mãe em atividades diárias de cuidados do primogênito. Além disso, de modo geral, as mães relataram estar mais cansadas e, conseqüentemente, menos dispostas a interagir e brincar com o(a) filho(a).

Dentre as limitações trazidas pela gestação, não poder pegar o primogênito no colo foi a mais ressaltada pelas mães e pareceu ser aquela mais sentida pelos primogênitos, conforme o relato das mães: "Eu acho que ele ficou muito chateado quando eu comecei a não pegá-lo mais no colo, assim, de erguê-lo, né. Ele pode vir no meu colo, comigo sentada, né. Não faz muito tempo, eu acho que faz um mês agora, que eu parei de pegar, porque eu comecei a ter muita contração" (M6).

Os momentos de brincadeira com o primogênito também sofreram mudanças no final da gestação. A este respeito tanto a freqüência das interações, quanto o estilo das brincadeiras precisou ser alterado para adaptar-se às limitações físicas da mãe: "Eu acho que, de repente, eu brinco menos de lutinha com ele hoje, dai ele já não gosta. Eu sempre brinquei com ele de lutinha e agora eu não posso. Ai, ele meio que cobra isso de mim: 'Quando é que tu vai poder?', 'Ah, quando $o S$. [segundo filho] chegar a mãe vai brincar de lutinha contigo," (M2); "Se são os jogos que eu posso botar numa mesa, tudo bem, agora sentar no chão eu não sento mais. Daí é banquinho, mas ainda assim eu não consigo alcançar direito as peças, e tá muito desconfortável. Daí eu tô brincando menos com ele" (M6).

A gestação também trouxe restrições às tarefas diárias de cuidados do primogênito, como dar banho, buscar na escola, entre outras: "Eu acho que ela se ressente um pouquinho da questão do vem me limpar, vem me dar banho. Quando eu entrei de repouso principalmente ficou mais claro para ela: 'Agora a minha mãe não pode me limpar. Agora a minha mãe não pode me dar banho. Agora a minha mãe não pode isso, não pode aquilo"," (M7).

O cansaço e a indisposição mencionados pelas mães no final da gestação também afetaram a interação mãe-primogênito: "A grande mudança é que eu tô muito cansada. Então, a disposição para brincadeiras, pra essas coisas, já reduziu faz muito tempo. Essa foi a grande mudança” (M6). "Acho que a vida continua normal lá em casa. A única coisa assim, é que agora eu tô cansada e tenho tido muito sono, vontade de dormir mais, ficar mais quieta. Eu chego em casa

3 Destaca-se que os dados referentes às limitações físicas associadas à gravidez basearam-se nos relatos das próprias mães, e não foram corroborados por avaliação médica e/ou através de exames físicos. 
e sempre peço pro H. [marido]: 'Ah, fica com o nenê pra mim descansar," (M8).

Frente a estas mudanças e ao perceberem as privações impostas ao primogênito, as mães buscaram alternativas para proporcionar momentos agradáveis de interações com as crianças: "Agora, questão de um mês atrás, me ocorreu uma alternativa pra agradar ele. Ele vem atrás de mim, nas costas, e vai na cacunda. Daí assim, parece que tá se agradando. Porque eu vinha falando pra ele que não era que eu não quisesse pegá-lo no colo, era que eu não conseguia mais. E eu acho que com essa alternativa ele tá mais tranqüilo agora” (M6); "Anteontem ela disse: 'Mãe, lembra quando eu deitava na cama e dormia no teu colinho? Posso deitar assim de novo?'. Eu disse: 'Pode'. Aí com esse barrigão deitei de lado na cama dela assim, tentava virar para um lado e não conseguia, para o outro não conseguia. Ela disse: 'Ai, mãe, tá difícil', eu disse: 'Tá difícil. Vamos dar um jeito'. Aí ela encostou a cabeça assim, meio sentada e conseguiu dormir." (M7).

No que se refere ao segundo tópico, a atenção dispensada ao primogênito pelas mães durante a gestação, os depoimentos indicam que a maioria das mães buscou dedicar mais tempo para estar com o filho durante este período. Em alguns casos, o maior tempo com o primogênito era conseqüência de intercorrências próprias da gravidez, como limitações físicas da mãe ou, inclusive, a necessidade de repouso: "Ai, a gente vai pra casa, lê historinha, pinta, desenha, joga, brinca, né. É um horário que a gente tem procurado dar mais atenção pra ela [primogênita]. A gente via muita televisão, 'Jornal Nacional', novela. A gente cancelou isso" (M4); "Eu tenho ficado muito com ela [primogênita], eu tô deixando de trabalhar muito pra ficar com ela. Então, de manhã eu tenho ficado muito com ela, fico até umas nove e meia, dez horas, ou chego mais cedo" (M5).

Em um dos casos, contudo, ocorreu uma situação inversa. Devido ao cansaço da mãe no final da gestação, mesmo nos momentos em que ela estava em casa, estava menos disponível ao primogênito e, logo, interagindo menos com este: "Eu já tinha reduzido bastante o tempo com o $P$. [primogênito]. Com a gravidez eu tô muito mais cansada. E eu só tenho tempo de descansar a noite. Tem muitas vezes, se eu ficar de bobeira nesse sofá aqui, olhando um pouco de TV, é pra já que eu durmo. E daí, muitas vezes passa duas horas e aí que eu vou acordar. E essas duas horas, os dois [primogênito e marido] ficaram aí, brincando de corrida e coisa e eu não vi o tempo passar" (M6).

Quanto às mudanças na tolerância com o primogênito, algumas mães mencionaram estarem mais tolerantes e compreensivas durante a gestação, enquanto outras referiram menos paciência neste período. $\mathrm{O}$ aumento da tolerância de algumas mães deveu-se à sua compreensão da gestação como um momento difícil para o primogênito, devido, entre outras coisas, à menor disponibilidade da mãe: "Eu acabo tolerando algumas coisas que antigamente eu não tolerava tanto, porque eu sei que algumas coisas eu não consigo dar pra ela nesse momento. Então, ela tem alguma razão de ficar, se for o caso, mais chateada ou mais incomodada. E dai eu tolerar um pouco mais essa coisa mais manhosa dela” (M1).

Nos casos em que as mães relataram menor tolerância com o primogênito durante a gestação, esta esteve acom- panhada de um aumento da irritabilidade da mãe e pouca aceitação das mudanças de comportamento expressas pelo primogênito: "Eu tô me percebendo mais intolerante na gravidez, sabe, mais irritada assim, porque eu tô com mais dificuldades de contornar algumas coisas. [...] Não é só com ela, é com tudo. Eu me sinto intolerante com a secretária, e com ele [marido]" (M4).

\section{Mudanças centradas no primogênito}

Nesta categoria, buscou-se investigar as mudanças no relacionamento mãe-primogênito centradas prioritariamente em alterações do comportamento dos primogênitos. Conforme os relatos maternos, as principais mudanças percebidas referiram-se aos seguintes temas: aumento na solicitação de atenção, aumento na dependência, propensão ao choro e "manha", comportamentos imitativos de bebês (ex. fala infantilizada, brincadeiras de ser bebê, problemas no controle esfincteriano, uso da mamadeira e chupeta) e aumento na agressividade.

Conforme os relatos a seguir, algumas mães referiram que, após sua gravidez, o primogênito passou a solicitar mais sua atenção. Isto coincidiu especialmente com o período de maior limitação física da mãe, no qual ela não poderia responder a todas as demandas da criança: "Ele tá normal, tá tranqüilo, tá super contente, fazendo as coisas que ele gosta, só eu acho que ele tá me solicitando um pouco mais por causa disso, né, que ele não quer deixar de ser o que ele é, que é filho único. [...] Eu acho que ele faz mais coisas pra chamar minha atenção" (M3); "Ela não dá uma folga, não deixa nem eu falar no telefone. [...] Alguma coisa ela faz pra chamar a atenção" (M5).

Outro aspecto do comportamento do primogênito destacado pelas mães referiu-se a um aumento em sua dependência em relação aos genitores, em especial à mãe. Esta mudança foi sentida, sobretudo, através de uma maior dificuldade do primogênito em separar-se da mãe. Segundo os relatos, o primogênito estaria expressando o medo de "perder" a mãe: "Acho que ele tem mais medo de ficar longe de mim depois que eu engravidei, medo de que eu vá deixá-lo, medo que eu vou esquecer dele. [...] Ele está mais dependente" (M3); "Ela não quer desgrudar nunca. Pra trabalhar, hoje de manhã, ela não queria deixar eu sair. De noite ela acorda e grita: 'Mamãe!', parece que eu fugi de casa, né. Coisa que ela não fazia antes. Então, algumas coisas em relação a mim, parece que eu vou fugir, parece que eu vou desaparecer de uma hora pra outra" (M5).

Em alguns casos o primogênito demonstrou uma preocupação maior com a mãe no período da gestação, o que poderia também ser pensado como reflexo do temor de "perdê-la": "Ele fica mais comigo. Esses tempos eu cheguei em casa com bastante dor, tri cansada. Aí, eu fiquei aqui deitada. Aí, quando eu vi, ele entrou, abriu a porta meio chorando: 'Mãe, eu não queria te deixar sozinha. Tu tá com dor. Eu vim ficar contigo,", (M2); "Sábado eu precisei trabalhar, o que é raro. Ela me ligou umas três vezes: 'Mamãe, a maninha tá bem? Tu tá bem? Tu não tá cansada?', (M5).

$\mathrm{O}$ aumento na dependência do primogênito em relação à mãe foi também evidenciado pelas mães ao relataram uma maior solicitação por parte da criança e uma aproximação 
maior da mãe. Durante a gravidez, e especialmente no período final, algumas mães relataram que os primogênitos passaram a demonstrar uma preferência pela mãe em detrimento do pai na realização de algumas tarefas: "Eu acho que aumentou um pouco o grude agora. [...] Mais comigo. Eu noto mais comigo uma dependência. Tem que ser a mamãe. A mamãe aqui, mamãe isso, mamãe aquilo. [...] É mais agora profinal, mais agora que a barriga ficou aparente" (M7); “Assim: 'Quer uma mamadeira?', 'Quero', 'Pai, faz uma mamadeira?', 'Não, a mãe que faz'. 'Filho, vamos escovar os dentes com o pai?', 'Não, a mãe que escova'. 'Eu fiz cocô', 'O pai vai', 'Não é a mãe que vai'. [...] Depois da gravidez, com certeza. Antes por ele tanto fazia” (M3).

Por fim, os comportamentos de maior dependência do primogênito tiveram reflexos expressivos em sua adaptação à escola. Algumas crianças passaram a não querer ficar na escola durante a gestação do irmão: "Uma coisa que ela está fazendo, é quando eu vou trabalhar, quando eu largo ela lá na escolinha: 'Ai, mamãe, fica comigo. Eu não quero me separar de ti'. [...] É um problema. Assim, sempre foi, só que agora está mais. Está mais difícil”" (M5).

Em alguns casos houve um episódio pontual de dificuldade na escola que as mães vincularam à época em que o primogênito ficara sabendo da notícia da gestação: " $O$ $P$. [primogênito] é uma criança que eu fiz adaptação uma vez na escola, depois eu nunca mais precisei, sempre foi tranqüilo. E tipo, uns três dias depois que ele ficou sabendo que eu tava grávida, eu fui levar ele e ele não queria entrar nem morto, se agarrou no meu pescoço, fez uma cena que eu jamais pensei que ele fizesse. [...] 'Ah, mas tu não vem, tu não vai me buscar?'. [...] Às vezes, ele diz pra mim: 'Ah, não esquece de mim. Mãe, não esquece de me buscar"” (M3).

As mães referiram perceber uma mudança também na propensão ao choro do primogênito. Segundo as mães, durante a gravidez o primogênito estaria mais "manhoso": "Ficou mais manhosa, um choro mais forçado" (M5); "Ele talvez esteja um pouco mais manhoso, de reclamar muito. Isso eu acho que ele piorou. [...] Ele anda meio com a tolerância baixa nos últimos tempos" (M6). Em um caso este aumento na propensão ao choro ou "manha" seria uma reação da primogênita por ter acompanhado os pais a uma sessão de ecografia: "Depois da primeira eco, durante uns quatro ou cinco dias, ela tava meio irritada, uma coisa meio manhosa, qualquer coisa ela tava chorando. [...] Quando ela foi na primeira ecografia, a gente acha que se concretizou pra ela. Ai, ela realmente viu que tinha um nenê" (M1).

Outra mudança percebida pelas mães no primogênito durante a gravidez foi a ocorrência de comportamentos imitativos de bebês, incluindo: fala infantilizada, brincadeiras de ser bebê, problemas com controle esfincteriano, uso da mamadeira ou chupeta. Durante a gestação da mãe, segundo os relatos, alguns primogênitos passaram fazer uso de uma fala infantilizada: "Agora ele começou a falar como bebê", (M6); "E aí ela começou a fazer uma voz de: 'Mãezinha, o que tu quer?'. [...] Ela deu uma mexida na voz pela primeira vez. Eu percebi isso ontem" (M7).

Comportamentos imitativos de bebê foram também evidenciados através de relatos de brincadeiras em que a criança assumia o papel de um bebê e solicitava o cuidado dos genitores: "Com a gente ela seguidamente tem feito esse tipo de brincadeira, de que ela é o bebezinho, ai ela não pode falar e não sei o quê e ela precisa de cuidados. Então, a gente entra na brincadeira dela [...]. 'Ah, agora eu sou a nenezinha!'”(M1). "Ultimamente, uma semana, duas pra cá, ele vai no berço, deita e diz: 'Mamãe, nhém, nhém, nhém', como se ele fosse bebê. Que ele é pequeno, que ele é o bebê, que ele não fala" (M3).

Em um caso, uma primogênita apresentou um episódio de perda de controle esfincteriano durante a noite no último trimestre de gestação materna. Esta teria sido a primeira vez que a primogênita fizera xixi na cama desde que adquiriu controle: "Pela primeira vez ela fez xixi na cama. Nunca fez na vida, desde que ela tirou a fralda. [...] E nunca escapou de noite. Então, não sei, foi uma reação fisiológica, ou se tem aí, algum psicológico. Porque nunca aconteceu. Mas me chamou atenção de novo, uma insegurança” (M7).

Outra primogênita, ainda, manifestou um súbito interesse pela mamadeira e chupeta após ficar sabendo da gestação da mãe. Neste caso, a primogênita nunca havia usado a mamadeira até então: "Ela chega e corre direto pra pegar o bico. [...] E ela não chupava bico, nem mamadeira. Ela nunca tomou mamadeira na vida. Desde o início do ano, quando eu descobri que estava grávida, ela começou a mexer no baú dos achados dela, de bebê e achou a mamadeira e começou a querer tomar água na mamadeira. Mas ela sabia que tinha aquela mamadeira lá, só que ela nunca tinha pedido pra tomar" (M5).

Por fim, algumas mães relataram que durante sua gestação o primogênito teria apresentado um aumento de agressividade. A este respeito, em um caso o aumento da agressividade do primogênito ocorreu na época em que ficara sabendo do sexo do segundo filho, que, diferentemente do desejado por ele, seria um menino: "Depois que ele soube [do sexo do bebê], ele meio que mudou. Ele começou a ficar um pouquinho mais agressivo. Porque ele tava dizendo pra todo mundo já que era menina. [...] Agressivo, assim, palavras, atitudes, de falar alguma coisa, irritado, chorão" (M2). Em um outro caso, ainda, uma primogênita apresentou um aumento de agressividade que pareceu estender-se ao longo da gestação e envolveu tanto os genitores quanto outras crianças e professores: "Esse ano, uma das questões bastante dificeis, ela tem batido muito, muito e nós temos sido chamados seguidamente na escola por problemas de conduta dela, de não ouvir o professor, de ficar falando, de dizer: 'Não vou dar bola pro que tu diz'. [...] Muito difícil com as outras crianças. Ela tem batido muito no colégio. [...] Nós nunca tínhamos tido esse problema com ela antes" (M4). Neste caso, o relacionamento mãe-primogênita tornou-se mais difícil e caracterizado por um maior enfrentamento: "Ela fica furiosa, dai chora: 'Tu é uma mãe chata. Eu não queria ter uma mãe como essa'. [...] Tudo isso é muito mais esse ano. Ela sempre foi provocativa e desafiadora, mas não como agora. E era muito mais com o pai do que comigo. Agora, ela tá mais comigo” (M4).

\section{Discussão}

Quanto ao relacionamento mãe-primogênito, destaca-se primeiramente os achados sobre as mudanças centradas na mãe. A este respeito, três mudanças principais foram eviden- 
ciadas por meio de seus relatos, a saber: limitações físicas, mudanças na atenção dispensada ao primogênito e maior tolerância/irritação com o primogênito. A principal mudança apontada pelas mães parece referir-se àquelas decorrentes das limitações físicas impostas pelo avançar da gestação do segundo filho. Neste sentido, todas as mães do presente estudo mencionaram restrições relacionadas com o aumento da barriga, e, em alguns casos a necessidade de repouso por indicação médica, incluindo não pegar o primogênito no colo, redução da freqüência e do estilo das brincadeiras e menor participação nas atividades diárias de cuidados do primogênito. Dentre estas, aquela mais acentuada pelas mães e que pareceu ter maior impacto sobre o primogênito referiu-se a não poder pegar a criança no colo. Além de o colo representar uma forma intensa de troca afetiva, esta mudança poderia trazer para o primogênito a ameaça de deixar de ocupar o lugar de bebê na família, de ser substituído pelo irmão que está para nascer.

Paralelamente a estas restrições, a maioria das mães buscou dedicar mais tempo para estar com o primogênito. Embora em um caso investigado tenha ocorrido uma situação contrária, a maioria das mães reduziu o período de trabalho para poder estar com a criança e, em alguns casos, a própria exigência de repouso levou a isto. Além disso, algumas mães referiram estar mais tolerantes com o primogênito durante a gestação. Estes dados corroboram a idéia defendida por Richardson (1981), de que as mães seriam capazes de empatizar com a criança em seu sofrimento por abandonar seu lugar de bebê na família e isto autorizaria alguns comportamentos que em outras circunstancias resultariam em punições ou repreensões.

Ressalta-se ainda, que as mães, conscientes das restrições impostas à interação com o primogênito, buscavam criar alternativas, adaptando as brincadeiras e o contato físico a fim de manterem-se próximas do primogênito durante a gestação. Estes comportamentos maternos de busca de mais tempo com o primogênito, alternativas para não minar os momentos de interação e maior tolerância, indicam um quadro de grande investimento e preocupação materna com a criança neste período. A mãe, consciente das mudanças no seu relacionamento com o primogênito e antevendo as limitações que surgiriam com a necessidade de dedicar-se aos cuidados de um recém-nascido, buscariam reverter este quadro através do apoio fornecido ao primogênito, de modo que este processo não lhe fosse penoso. Todos estes comportamentos caracterizam o que a literatura descreve como apoio parental e endossam a idéia de que o período anterior ao nascimento de um irmão seria caracterizado pelo aumento nos níveis de apoio emocional e estimulação cognitiva fornecidos ao primogênito, enquanto os pais buscariam preparar a criança para o iminente nascimento (Kowaleski-Jones \& Dunifon, 2004). Contudo, a conseqüente melhora no bem-estar do primogênito relatada por estes autores não se confirmou no presente estudo, uma vez que os primogênitos tenderam a ser descritos como mais ansiosos, irritados, inseguros e, inclusive, infelizes ao final da gestação do que no momento que receberam a notícia da gravidez e antes disso.

Embora as mães buscassem estar mais tempo com o primogênito, adaptando-se as suas atividades, preservando-o e sendo mais tolerantes, não se pode negar as limitações enfatizadas pelas mães, tanto em relação à interação mãe-primogênito, como em termos de sua freqüência e qualidade. A gestação e, de modo marcante, o último trimestre gestacional foi descrito pelas mães como um período em que se encontravam mais cansadas e indispostas, além de, como já referido anteriormente, mais abatidas pelas intensas demandas e preocupações deste período. Estes achados corroboram o apontado por Richardson (1983) que caracterizou o período final da gestação como um momento pouco favorável para a relação mãe-criança. Segundo o autor, a mãe estaria cansada e indisposta e o primogênito estaria mais exigente e irritável.

Ainda no que se refere à relação mãe-primogênito, tomando como foco as mudanças centradas no primogênito, percebe-se que a gestação materna constitui-se em um evento marcante na vida do primogênito com diversos reflexos nos seus comportamentos, como os revelados no presente estudo, por exemplo aumento na solicitação de atenção, aumento na dependência, propensão ao choro e "manha", comportamentos imitativos de bebês (ex. fala infantilizada, brincadeiras de ser bebê, problemas no controle esfincteriano, uso da mamadeira e chupeta) e aumento na agressividade. Conforme os resultados expostos, durante a gestação, os primogênitos tornaram-se mais exigentes, solicitando a atenção materna e seu envolvimento. Além disso, algumas mães referiram uma maior aproximação do primogênito em relação a elas, de modo que as crianças passaram a demonstrar uma preferência pela mãe em detrimento do pai na realização de algumas tarefas diárias. Alguns relatos indicaram que os primogênitos passaram a solicitar o envolvimento da mãe, inclusive em tarefas que até então realizavam sozinhos, como ir ao toalete. Isto indica que os primogênitos estariam esforçando-se para chamar a atenção da mãe para si, em contrapartida ao envolvimento dela com o bebê que estava para nascer.

A principal mudança apontada pelas mães nos comportamentos do primogênito referiu-se ao aumento em sua dependência com relação aos genitores, em especial à mãe. Diversas mães relataram uma maior dificuldade do primogênito em afastar-se delas durante a gravidez, o que era compreendido como um temor em perdê-las. A este respeito, foi mencionado, por exemplo, que as crianças não queriam mais dormir fora de casa, ficar na casa de parentes ou amigos sem a mãe e queriam saber onde a mãe estava. Esta maior dependência teve reflexos também na adaptação de algumas crianças à escola, trazendo dificuldades na separação da mãe neste momento. Em alguns casos esta dificuldade esteve relacionada ao momento em que a criança fora informada da gravidez e em outros ocorreu no período final da gestação.

Outras mudanças apontadas pelas mães incluíram maior propensão ao choro ou "manha" e ocorrência de comportamentos imitativos de bebês, tais como fala infantilizada, brincadeiras de ser bebê, problemas com controle esfincteriano, uso da mamadeira ou chupeta. Ressalta-se que, tanto no caso em que ocorreu um retrocesso no controle esfincteriano, quanto no caso em que a criança passou a fazer uso da mamadeira, estas foram as primeiras vezes em que ocorreram tais comportamentos, o que denota a intensa ansiedade associada ao momento do nascimento do irmão. Frente a isso, destaca-se que os pais tenderam a mostrar-se tolerantes e compreensivos com os primogênitos, participando com eles na brincadeira de ser bebê, tratando com naturalidade o xixi 
na cama e não proibindo o uso da mamadeira ou da chupeta. O único comportamento pouco aceito pelos genitores referiu-se à fala infantilizada, considerada por eles inadequada à idade da criança.

Por fim, alguns relatos apontaram para um aumento da agressividade do primogênito tanto em relação à mãe, como com outras crianças e professores. Destaca-se que no caso em que houve maior enfrentamento na relação mãe-primogênito, esta criança já havia sido descrita como difícil anteriormente à gestação do irmão e, além disso, vivenciara diversas outras mudanças em sua vida neste período, o que incluiu mudança de escola, de pessoa cuidadora, perda de um animal de estimação, nascimento de um primo e uma crise conjugal dos pais.

Estes resultados demonstram a sensibilidade do primogênito às mudanças percebidas no funcionamento familiar e no relacionamento desfrutado com a mãe já no período que antecede ao nascimento do irmão. Achados semelhantes foram relatados por Dessen e Mettel (1984) que, através de um estudo de caso com uma família brasiliense, encontraram alterações no comportamento do primogênito desde a época em que ele fora informado da gestação do irmão. Neste estudo, as mudanças envolveram alterações no controle esfincteriano noturno, nas exigências com relação à mãe e em comportamentos como birra e uso de chupeta, todas estas também referidas no presente estudo.

Destaca-se ainda, que os comportamentos do primogênito no período gestacional relatados pelas mães do presente estudo, também se assemelharam àqueles referidos pela literatura que trata do impacto do nascimento do segundo filho para o primogênito. Conforme alguns autores (Dunn \& Kendrick, 1980, 1986; Field \& Reite, 1984; Stewart \& cols., 1987), após o nascimento do irmão a grande maioria das crianças passaram a apresentar aumento na dependência, na propensão ao choro, nas condutas caprichosas, na confrontação com a mãe e mais comportamentos imitativos de bebê (i.e. fala infantilizada, pedido de colo, retrocesso na aprendizagem de hábitos de toalete). Pode-se supor que vários destes comportamentos que podem até se intensificar com o nascimento do bebê, já estariam presentes desde o período gestacional. Isto apóia a idéia de que o ajustamento e a aflição expressos pelo primogênito nos últimos meses de gestação seriam similares e o melhor preditor de seu ajustamento nos meses seguintes ao nascimento do irmão (Gottlieb \& Baillies, 1995; Stewart \& cols., 1987).

Endossando a literatura (Dunn \& Kendrick, 1980, 1986; Field \& Reite, 1984; Stewart \& cols., 1987), no presente estudo, os comportamentos de maior dependência do primogênito foram bastante enfatizados pelas mães e incluíram dificuldade em se afastar da mãe (ex.: para ir à escola), maior solicitação pela mãe (inclusive em tarefas que até então realizava sozinho) e preocupação com a mãe. De fato, como enfatizado por Gottlieb e Baillies (1995), a gestação caracterizaria o início do processo de tornar-se irmão, através da concretização da realidade do bebê. Segundo os autores, este processo poderia minar temporariamente a segurança e a confiança do primogênito, que necessitaria mais atenção e apoio dos genitores.

A partir da Teoria do Apego (Bowlby, 1984), pode-se entender algumas das mudanças de comportamento do primogênito durante a gestação materna, pois a relação mãe-criança, que se constitui em fonte primária de apego nos primeiros anos de vida da criança, passa a ser ameaçada pelo irmão que vai nascer. Assim, para crianças pequenas, o nascimento de um irmão e a consequente redução no acesso à mãe, pode representar uma ameaça ao relacionamento primário e afetar os padrões de apego existentes (Bowlby, 1984). O rompimento do laço de apego ao cuidador primário poderia, então, conduzir a comportamentos similares àqueles utilizados pelos bebês a fim de manter seu apego aos cuidadores (ex. agarrar-se, aproximação da mãe, choro, protesto). Deste modo, Neubauer (1982) já havia proposto que tais comportamentos fossem compreendidos como parte da intensificação do apego da criança à mãe a fim de manter os padrões de vinculação desfrutados até o momento.

Trause e Irvin (1992) endossaram esta idéia ao afirmar que frente a eventos estressante como o nascimento de um irmão, a segurança de apego de qualquer criança pode vacilar, tornando fundamental o apoio e o conforto proporcionado pelos genitores. Como apontado por Raphael-Leff (1997), além de dar as boas-vindas ao bebê, o primogênito terá que fazer difíceis concessões após o nascimento do segundo filho, cedendo 'território', posses e atenção, enquanto precisa modificar seu lugar na hierarquia familiar. Muitas destas concessões já seriam antecipadas durante a gestação.

Com a aproximação do parto, a mãe precisa investir no novo filho e voltar-se para si mesma. Conforme Raphael-Leff (1997), durante a gravidez, o espaço físico da gestante, assim como seus pensamentos tornam-se ocupados pelo bebê crescendo dentro dela, mesmo enquanto convive com o primogênito em seu colo. Assim, a mãe precisa desligar-se de certa forma do primogênito para fazer a maternagem do segundo filho (Richardson, 1983; Raphael-Leff, 1997). Apesar de todas as intenções no sentido contrário, mesmo durante a gestação, quando a mãe se volta para seu bebê em gestação, afasta-se imperceptivelmente do primogênito (Brazelton \& Sparrow, 2003). Em alguns casos, a mãe terá clara consciência deste deslocamento de investimento e da mudança que o bebê trará à sua relação com o primogênito, de modo que poderá dedicar-se mais intensamente ao filho mais velho no período gestacional (Raphael-Leff, 1997). $\mathrm{Na}$ verdade, parte da tolerância materna em relação ao primogênito, revelada pelas mães do presente estudo, poderia indicar a relutância da própria mãe em abandonar a relação especial compartilhada entre ela e o primogênito (Richardson, 1983). Neste sentido é plausível se esperar destas mães certa ambivalência ou tristeza por tirar o primogênito de seu lugar de bebê e filho único da família, e por ter de re-significar a relação diádica íntima e exclusiva com o ele.

Para as mães do presente estudo, a gestação do segundo filho representou um momento de redefinição de seu papel de mãe e de sua relação com o primogênito. Apesar do cansaço, do tamanho da barriga que limitava suas atividades, as mães demonstraram esforçar-se para dedicar atenção e, inclusive, mais tempo para ficar com o primogênito neste período. Frente a todas as mudanças deste período de transição, embora os genitores busquem apoiar, preparar e cuidar atentamente do primogênito, não podem imunizá-lo das ansiedades e angústias. Com isso, as mudanças no comportamento do primogênito podem ser compreendidas como uma busca por 
reaver os padrões de interações e envolvimento desfrutados com a mãe até o momento e adequar-se à nova realidade que já se apresenta com a gestação e tende a se impor com maior intensidade após o nascimento do irmão.

Assim, desde a gestação já se iniciaria o processo de transição para a inclusão do novo membro à família. Além disso, acredita-se que o período que antecede ao nascimento do segundo filho influenciaria o modo como o primogênito vai lidar com o nascimento do irmão e a própria relação fraterna. Com isso, ressalta-se a importância do apoio dos genitores e das relações estabelecidas entre a família durante a gestação como modo de favorecer a adaptação familiar ao nascimento do segundo filho. Neste sentido, é de fundamental importância o apoio fornecido pelo pai e por toda a rede de apoio familiar à mãe e ao primogênito. Enquanto a relação com a mãe passa por mudanças marcantes no final da gestação, o pai pode servir como figura de continuidade na vida do primogênito, favorecendo o sentimento de confiança desta criança.

A este respeito, Dessen (1997) afirmou que a complementaridade entre o casal parental na busca por um novo ajuste na distribuição de suas atribuições seria uma das principais tarefas familiares de adaptação para a chegada do segundo filho. Como descrito na literatura, o marido se constituiria na principal fonte de apoio durante a gestação e nos primeiros meses de vida do bebê (Belsky, 1981; Dessen \& Braz, 2000). Quanto à adaptação do primogênito, a literatura destaca que uma relação próxima com o pai e o envolvimento deste com o primogênito favoreceria o ajustamento da criança no momento do nascimento do irmão, de modo que o primogênito ficaria menos aborrecido pelo envolvimento da mãe com o recém-nascido, apresentando menos conflito com a mãe e uma melhor aceitação do bebê (Dunn \& Kendrick, 1986; Legg, Sherick \& Wadland, 1974).

Antes de concluir, é importante destacar que as participantes do presente estudo constituíam um grupo com algumas características particulares que devem ser consideradas na compreensão dos resultados. Destaca-se que todas elas haviam planejado a gestação do segundo filho, possuíam nível socioeconômico de médio a alto, eram adultas, casadas e viviam seu primeiro casamento. As características mencionadas podem ter contribuído em seu conjunto como facilitadoras da transição para o nascimento do segundo filho. Contudo, esta seria uma realidade bastante particular e não representativa de um grande número de famílias brasileiras que nem semprepossuem suas necessidades básicas atendidas. Por outro lado, as famílias de hoje incluem configurações familiares muito variadas, extrapolando o modelo nuclear investigado neste estudo. Todas estas variações não contempladas no presente estudo podem constituir-se em fatores de aumento da complexidade do fenômeno investigado, devendo ser consideradas em novos estudos.

Por fim, ressalta-se que pontos de transição como o nascimento do segundo filho podem ser períodos de maior risco para disfunções familiares. A necessidade de reorganização da família pode criar novas vulnerabilidades e dificuldades. Devido à oportunidade de mudança presente, focar esforços de prevenção e intervenções nestes períodos seria muito efetivo. Neste sentido, os resultados deste estudo devem servir como apoio para possíveis programas de intervenção para genitores envolvidos no processo de transição para o nascimento do segundo filho. Enquanto existem diversos programas para pais que esperam seu primeiro filho, não se encontrou programas específicos para pais que esperam seu segundo filho. Na maioria dos casos, não são dadas diretrizes sobre mudanças esperadas nos comportamentos e na estrutura que envolve as relações familiares desde o período gestacional até a chegada do segundo filho. Além disso, a importância de tais intervenções estaria em preparar e conscientizar os genitores da relevância de seu papel junto ao primogênito neste período e para as mudanças nas relações familiares tendem a acontecer.

\section{Referências}

Bardin, L. (1977). Análise de Conteúdo. (L. Reto \& A. Pinheiro, Trans.) São Paulo: Edições 70/Livraria Martins Fontes.

Baydar, N., Greek, A., \& Brooks-Gunn, J. (1997). A longitudinal study of the effects of the birth of a sibling during the first six years of life. Journal of Marriage and the Family, 59, 939-956.

Belsky, J. (1981). Early human experience: A family perspective. Developmental Psychology, 17, 3-23.

Bourguignon, O., Alary, A., Butat, M., Cessans, A., Coloignier, R., Duvillie-Moustacchi, R., Hirsch-Pelissier, A., JaurandBulvestre, A., Ouassini, M., Nzeyimana, N., Salmon, N., \& Samama, C. (1980). Changes in the family with the arrival of a second child. Bulletin de Psychologie, 34, 289-304.

Bowlby, J. (1984). Apego e Perda. São Paulo: Martins Fontes.

Brazelton, B., \& Sparrow, J. (2003). Três a seis anos: Momentos decisivos do desenvolvimento infantil. (C. Monteiro, Trad.) Porto Alegre: Artes Médicas.

Dessen, M. (1997). Desenvolvimento familiar: Transição de um sistema triádico para poliádrico. Temas em Psicologia, 3, 51-61.

Dessen, M., \& Braz, M. (2000). Rede social de apoio durante transições familiares decorrentes do nascimento de filhos. Psicologia: Teoria e Pesquisa, 16, 221-231.

Dessen, M., \& Mettel, T. (1984). Interação pais-primogênito quando da chegada de uma segunda criança na família: Um estudo de caso. Psicologia, 10, 27-39.

Dunn, J., \& Kendrick, C. (1980). The arrival of a sibling: Changes in patterns of interaction between mother and first-born child. Journal of Child Psychology and Psychiatry, 21, 119-132.

Dunn, J., \& Kendrick, C. (1986). Hermanos y hermanas: Amor, envidia y comprensión. (C. Barrio, B. Barrio \& B. Slobodziaanek, Trans.) Madrid: Alianza Editorial.

Field, T., \& Reite, M. (1984). Children's responses to separation from mother during the birth of another child. Child Development, 55, 1308-1316.

Gottlieb, L., \& Baillies, J. (1995). Firstborns' behaviors during a mother's second pregnancy. Nursing Research, 44, 356-362.

Gottlieb, L., \& Mendelson, M. (1990). Parental support and firstborn girl's adaptation to the birth of a sibling. Journal of Applied Developmental Psychology, 11, 29-48.

Jenkins, P. (1976). Conflicts of a secundigravida. Maternal-Child Nursing Journal, 5, 117-126.

Kowaleski-Jones, L., \& Dunifon, R. (2004). Children's home environment: Understanding the role of family structure changes. Journal of Family Issues, 25, 3-28. 
Kreppner, K., Paulsen, S., \& Schuetze, Y. (1982). Infant and family development: From triads to tetrads. Human Development, 25, 373-391.

Laville, C., \& Dionne, J. (1999). A construção do saber: Manual de metodologia de pesquisa em ciências humanas. Porto Alegre: Artes Médicas.

Legg, C., Sherick, I., \& Wadland, W. (1974). Reaction of preschool children to the birth of a sibling. Child Psychiatry and Human Development, 5(1), 3-39.

Murphy, S. (1993). Siblings and the new baby: Changing perspectives. Journal of Pediatrics Nursing, 8, 277-288.

Neubauer, P. B. (1982). Rivalry, envy, and jealousy. Psychoanalytic Study of the Child, 37, 121-142.

Núcleo de Infância e Família - NUDIF/UFRGS/CNPq (2005a). Ficha de Contato Inicial. Instrumento não-publicado. Instituto de Psicologia. Universidade Federal do Rio Grande do Sul.

Núcleo de Infância e Família - NUDIF/UFRGS/CNPq (2005b). Entrevista de Dados Demográficos do Casal. Instrumento não-publicado. Instituto de Psicologia. Universidade Federal do Rio Grande do Sul.

Núcleo de Infância e Família - NUDIF/UFRGS/CNPq (2005c). Entrevista sobre a Gestação e as Expectativas da Gestante (terceiro trimestre de gestação). Instrumento não-publicado. Instituto de Psicologia. Universidade Federal do Rio Grande do Sul.

Núcleo de Infância e Família - UFRGS/CNPq (2005d). Entrevista com a Mãe sobre o Impacto da Gestação do Segundo Filho na Dinâmica Familiar (terceiro trimestre de gestação). Instrumento não-publicado. Instituto de Psicologia. Universidade Federal do Rio Grande do Sul.

Núcleo de Infância e Família - NUDIF/UFRGS/CNPq (2005e). Entrevista sobre a Experiência da Maternidade (Primogênito com idade entre três e seis anos). Instrumento não-publicado. Instituto de Psicologia. Universidade Federal do Rio Grande do Sul.

Piccinini, C., Lopes, R., Rossato, C., \& Oliveira, D. (2005). Estudo longitudinal sobre o impacto do nascimento do segundo filho na dinâmica familiar e no desenvolvimento emocional do primogênito. Manuscrito não-publicado, Pós-Graduação em Psicologia do Desenvolvimento, Universidade Federal do Rio Grande do Sul, Porto Alegre.
Raphael-Leff, J. (1997). Gravidez: A história interior. Porto Alegre: Artes Médicas.

Richardson, P. (1981). Women's perceptions of their important dyadic relationships during pregnancy. Maternal-Child Nursing Journal, 10, 159-174.

Richardson, P. (1983). Women's perceptions of changes in relationships shared with children during pregnancy. MaternalChild Nursing Journal, 12, 75-88.

Stake, R. E. (1994). Case Studies. In N. Denzin \& Y. Lincoln (Eds.), Handbook of qualitative research (pp. 236-247). London: Sage.

Stewart, R. B., Mobley, L. A., Van-Tuyl, S., \& Salvador, M.A. (1987). The firstborn's adjustment to the birth of a sibling: A longitudinal assessment. Child Development, 58, 341-355.

Teti, D., Sakin, J., Kucera, E., Corns, K., \& Eiden, R. (1996). And baby makes four: Predictors of attachment security among preschool-age firstborns during the transition to siblinghood. Child Development, 67, 579-596.

Trause, M., \& Irvin, N. (1992). Atendimento aos irmãos. In M. Klaus \& J. Kennell (Eds.), Pais/Bebê: A formação do apego (pp.129-148). Porto Alegre: Artes Médicas.

Tudge, J., \& Frizzo, G. (2002). Classificação baseada em Hollingshead do nível socioeconômico das famílias do Estudo Longitudinal de Porto Alegre: da Gestação à Escola. Manuscrito não publicado. Porto Alegre. Instituto de Psicologia. Universidade Federal do Rio Grande do Sul.

Walz, B., \& Rich, O. (1983). Maternal tasks of taking-on a second child in the postpartum period. Maternal-Child Nursing Journal 12, 185-216. 